\title{
Correction to: $P$-values should not be used for decision making in the practice of clinical medical physics
}

\author{
Parminder Basran ${ }^{1} \cdot$ Giuseppe Palma ${ }^{2} \cdot$ Clive Baldock $^{3}$
}

Published online: 22 November 2021

(c) Australasian College of Physical Scientists and Engineers in Medicine 2021

\section{Correction to: \\ Physical and Engineering Sciences in Medicine https://doi.org/10.1007/s13246-021-01068-1}

In the original text, Professor Basran inadvertently excluded the word 'not' from the sentence 'The $p$-value is not the probability of this hypothesis' in the 2nd paragraph of his opening statement. This has been addressed by Professor Basran in his Letter to the editor which further clarifies the definition (https://doi.org/10.1007/s13246-021-01074-3).

Readers are asked to note that Professor Palma's rebuttal in the debate is to the original text, not the amended text seen in the updated version of the article. Although this does slightly change aspects of the debate, it is important to correct the statement so that an incorrect definition does not propagate and lead to misinterpretation of the $p$-value.

Publisher's Note Springer Nature remains neutral with regard to jurisdictional claims in published maps and institutional affiliations.

The original article can be found online at https://doi.org/10.1007/ s13246-021-01068-1.

Clive Baldock

c.baldock@westernsydney.edu.au

1 Department of Clinical Sciences, College of Veterinary Medicine, Cornell University, Ithaca, NY 14853, USA

2 Institute of Biostructures and Bioimaging, Italian National Research Council (CNR), Naples, Italy

3 Graduate Research School, Western Sydney University, Penrith, NSW 2747, Australia 